Науковий вісник Нлту України
Scientific Bulletin of UNFU
https://nv.nltu.edu.ua
$\begin{gathered}\text { https://doi.org/10.36930/40290921 } \\ \text { Article received 05.11.2019 p. } \\ \text { Article accepted 26.12.2019 p. } \\ \text { UDK 66.06:532.529 }\end{gathered}$

В. І. Орел, Б. С. Піцишин, І. Ю. Попадюк

Національний університет "Львівська політехніка", м. Львів, Україна

\title{
ВИКОРИСТАННЯ ЗМІШУВАЧА НОВОЇ КОНСТРУКЦІЇ ДЛЯ ПРИГОТУВАННЯ ВОДНИХ РОЗЧИНІВ ПОЛІАКРИЛАМІДУ В ПОТОЦІ ТЕЙЛОРА-КУЕТТА
}

Подано результати експериментальних досліджень впливу ексцентриситету ротора відносно статора та розчинів поліакриламіду на коефіцієнт тертя в потоці Тейлора-Куетта. Кільцевий проміжок між ротором із діаметром 113 мм і статором із діаметром 142 мм заповнено водними розчинами поліакриламіду масовою концентрацією 100 ррт. Кільцевий проміжок між поверхнями циліндрів, який відповідав коаксіальному їх розташуванню, трансформувався у замкнений конфузорно-дифузорний під час зміни положення зовнішнього циліндра відносно внутрішнього. Виявлено залежність коефіцієнта тертя від числа Рейнольдса, ширини проміжку між ротором і статором за їх аксіального розташування та концентрації водних розчинів поліакриламіду. Зі збільшенням числа Рейнольдса спостережено зменшення коефіцієнта тертя для дослідженої концентрації розчину поліакриламіду, порівняно з водою. Для однакових значень числа Рейнольдса за концентрації розчину поліакриламіду 100 ppm отримано зменшення коефіцієнта тертя, порівняно з водою. Збільшення коефіцієнта тертя для дослідженої концентрації розчину поліакриламіду одержано зменшенням ширини проміжку. Для водних розчинів поліакриламіду, порівняно з водою, перше критичне число Рейнольдса має менше значення. При цьому значення коефіцієнта тертя, що відповідає цьому числу Рейнольдса, є більшим. Отримані результати свідчать про можливість приготування водних розчинів поліакриламіду в запропонованому змішувачі з використанням електродвигуна з регульованою швидкістю обертання.

Ключові слова: ексцентричні циліндри; ротор; коефіцієнт тертя; крутний момент; потік Тейлора-Куетта; число Рейнольдса.

Вступ. Екологічна безпека систем, що транспортують стічні води, є надзвичайно актуальною (Alekseev et al., 1991). Оскільки мережа дощової каналізації є обмеженою через витрату, то за екстремальних перевантажень у періоди інтенсивних дощів виникає проблема іiї експлуатації. Використання гідродинамічно активних полімерів (ГДАП) призводить до відновлення нормального функціонування трубопроводів збільшенням їх пропускної здатності завдяки зменшенню гідравлічного тертя (Zhuk \& Orel, 1995; John, 2011; Andrade et al., 2011; Khadom \& Abdul-Hadi, 2014). Періодичність і коротка тривалість використання ГДАП у таких ситуаціях роблять їхнє застосування обгрунтованим.

ГДАП у вигляді розчину доцільно використовувати лише там, де має значення швидкість їхнього розчинення. Під час приготування водних розчинів ГДАП застосовують лопатеві мішалки 3 малою кількістю обертів. При цьому відбувається їхня деструкція внаслідок механічного руйнування молекул (Kozlov, 1987; Povkh, 1982; Kaboorani \& Riedl, 2015; Wagih Abu Rowin et al., 2018). Це призводить до зниження чи повного припинення впливу ГДАП на гідравлічний опір.

Для запобігання руйнуванню молекул ГДАП було запропоновано змішувач (Cherniuk \& Pitsyshyn, 2018), який містить привід обертання ротора, що розташований у циліндричній ємності, яка закріплена з можливістю повороту відносно матеріальної осі, котра не збігається 3 геометричною віссю ємності. Змішувач оснащений реверсивним приводом для обертання ємності відносно матеріальної осі, що знаходиться на зовнішній бічній поверхні ємності, й обмежувачами переміщення ємності.

Аналіз літературних джерел. Потік рідини, що виникає між двома обертовими концентричними циліндрами, відомий як потік Тейлора-Куетта, в якому замкнута геометрія дає змогу уникати деградації розчину ГДАП лопатями мішалки.

У потоці Тейлора-Куетта зі зміною кутової швидкості внутрішнього або зовнішнього циліндра спостерігають кілька режимів течії - від ламінарного до турбулентного. Тейлор (Taylor, 1923) у своїх експериментах зосереджувався на первинних нестабільностях потоку Тейлора-Куетта - тороїдальних вихорах, які послідовно поширювалися до осі циліндра і були набагато меншими за високотурбулентних режимів. Давей (Davey, 1962) чисельним розрахунком визначив крутний момент, що діє на циліндри в потоці з вихорами Тейлора. Коул (Cole, 1976) спостерігав друге критичне число

Інформація про авторів:

Орел Вадим Ігорович, канд. техн. наук, доцент, кафедра гідравліки і сантехніки. Email: vadim_orel@yahoo.com

Піцишин Богдан Степанович, ст. викладач, кафедра гідравліки і сантехніки. Email: pbsgs@ukr.net

Попадюк Ігор Юрійович, канд. техн. наук, доцент, кафедра гідравліки і сантехніки. Email: popaduk_i@ukr.net

Цитування за ДСтУ: Орел В. І., Піцишин Б. С., Попадюк І. Ю. Використання змішувача нової конструкції для приготування водних розчинів поліакриламіду в потоці Тейлора-Куетта. Науковий вісник Нлту України. 2019, т. 29, № 9. С. 121-125.

Citation APA: Orel, V. І., Pitshyshyn, B. S., \& Popadyuk, І. Yu. (2019). Use of the mixer of modern construction for preparation of the polyacrylamide water solutions in the Taylor-Couette flow. Scientific Bulletin of UNFU, 29(9), 121-125.

https://doi.org/10.36930/40290921 
Рейнольдса і провів візуалізацію потоку з подальшим збільшенням кутової швидкості. За межами першого критичного числа Рейнольдса спостерігали хвилеподібний вихоровий потік. Вимірюванням крутного моменту доведено, що вихровий потік Тейлора стає нестійким за цією критичною точкою, що підтверджено експериментами в різних діапазонах співвідношень радіусів та висот циліндрів (Huisman et al., 2013; Adebayo et al., 2018; Adebayo \& Rona, 2015; Campolo et al., 2015).

Для вивчення ефекту зменшення тертя в потоці Тейлора-Куетта під час обертання внутрішнього циліндра Йонес та Маршалл (Jones \& Marshall, 1969) використовували водні розчини поліакриламіду (ПАА) малих концентрацій. Гроісман і Стеінберг (Groisman \& Steinberg, 1996) виявили значний вплив розчинів ПАА на структуру і стабільність потоку Тейлора-Куетта. Візуалізувалися дві нові коливальні структури, які пояснювали еластичністю рідини. Ї та Кім (20) спостерігали зниження критичного числа Тейлора в потоці ТейлораКуетта з підвищенням концентрації ПАА.

Дослідники (17), (21-24) також проводили дослідження із зменшення опору в потоці Тейлора-Куетта 3 використанням інших полімерів, поверхнево-активних речовин тощо. У роботах (Dutcher \& Muller, 2009; Greidanus et al., 2011; Srinivasan et al., 2015; Eskin, 2014; Greidanus et al., 2015) досліджували розчини різних додатків у системі Тейлора-Куетта з різними модифікаціями поверхонь циліндрів.

Об'єкт дослідження - течія водних розчинів ГДАП у пропонованому змішувачі.

Предмет дослідження - методи і засоби визначення впливу режимів руху водних розчинів ГДАП у потоці Тейлора-Куетта та неспіввісності ротора та статора змішувача на коефіцієнт тертя.

Мета роботи - дослідити приготування водних розчинів ГДАП у потоці Тейлора-Куетта, що має місце в пропонованому змішувачі.

Для досягнення зазначеної мети потрібно виконати такі основні завдання дослідження:

- виявити залежність коефіцієнта тертя від числа Рейнольдса;

- встановити ширину проміжку між циліндрами за їх ексцентричного розташування та водних розчинів ПАА порівняно з водою.

Наукова новизна дослідження полягає в тому, що розроблено метод, який дає змогу за рахунок зменшення ширини проміжку отримати збільшення коефіцієнта тертя для дослідженої концентрації водного розчину ПАА.

Практична значущість дослідження полягає в тому, що отримані результати свідчать про можливість приготування водних розчинів ПАА в запропонованому змішувачі з використанням електродвигуна з регульованою швидкістю обертання.

Матеріал і методи дослідження. Експериментальний стенд. Експериментальні дослідження проводили на експериментальному стенді (Popadiuk et al., 2018) (рис. 1). Статор 1 діаметром 142 мм закріплений на плиті 2, що встановлена $з$ можливістю зворотно-поступального переміщення на опорній плиті 4. У порожнині статора розміщений гладкий ротор 5 діаметром 113 мм 3 неіржавіючої сталі, що з'єднаний з електродвигуном 7, який жорстко закріплений відносно опорної плити. Вал двигуна 6 пропущений через отвір у герметичній кришці 8, що закріплена на статорі. Статор висотою

15,3 см - це металевий каркас 9 з вікнами, в середині якого жорстко прикріплено прозорий циліндр 10. Переміщення статора і його неспіввісність $з$ ротором контролюється стрілкою, яка закріплена до рухомої плити, відносно шкали 14 на опорній плиті 4.

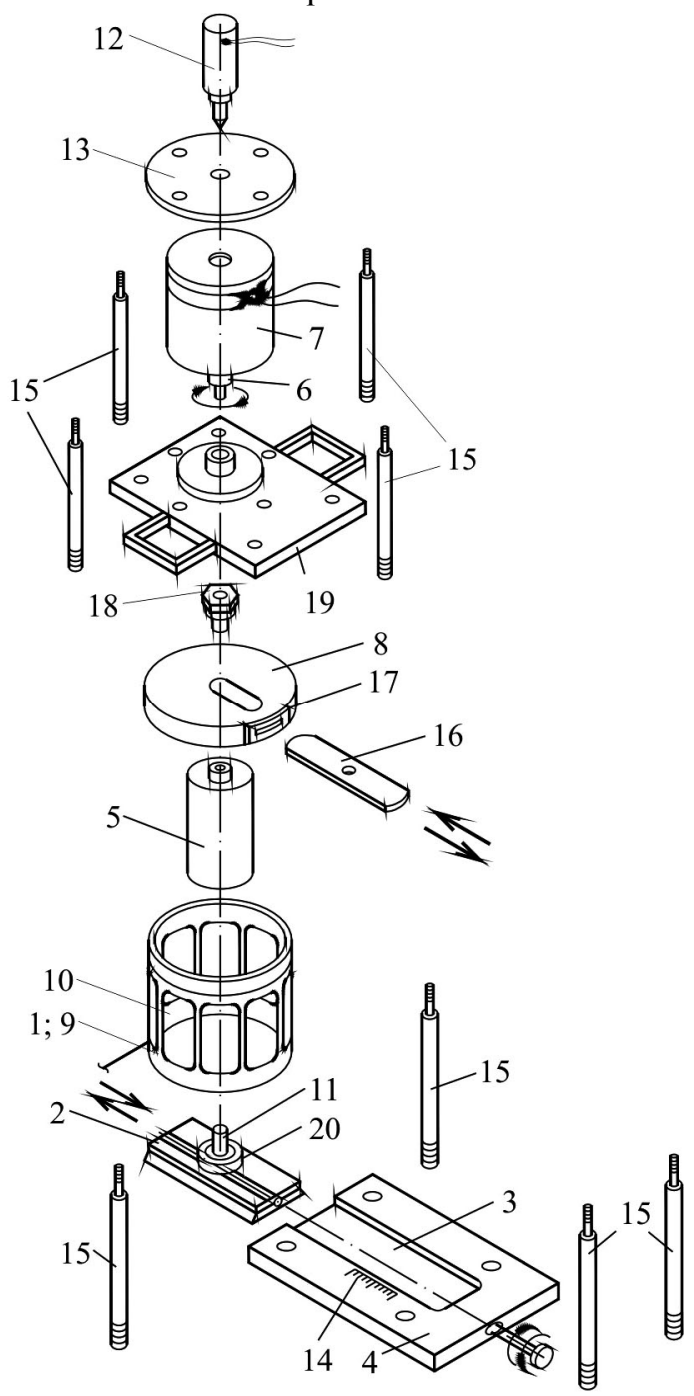

Рис. 1. Схема експериментального стенду: 1) статор; 2) плита рухома; 3) паз; 4) опорна плита; 5) ротор; 6) вал; 7) електродвигун; 8) кришка; 9) металевий каркас; 10) прозорий циліндр; 11) вісь; 12) тахометр; 13) плита; 14) шкала; 15) стойка; 16) ущільнювальна пластина; 17) ущільнення; 18) проміжна втулка; 19) плита; 20) обойма

Кільцевий проміжок між поверхнями ротора і статоpa, який відповідав концентричному їх розташуванню, змінювався у замкнений конфузорно-дифузорний під час зміни положення статора (рис. 2).

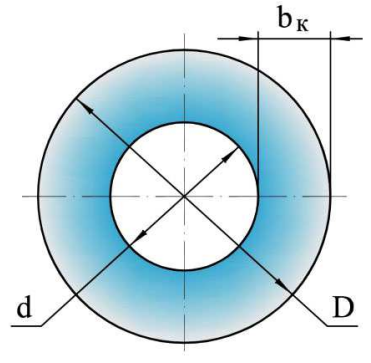

a)

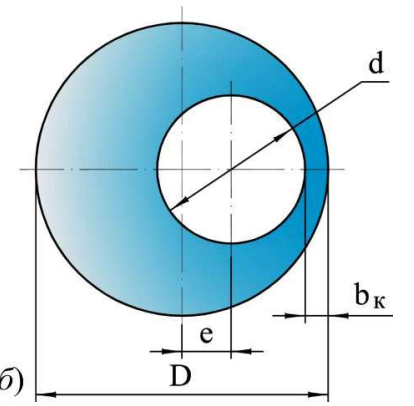

Рис. 2. Схеми розташування ротора та статора: а) коаксіальне; б) аксіальне; $\mathrm{e}$ - ексцентриситет; $b_{\mathrm{\kappa}}$ - ширина проміжку за коаксіального (концентричного) розташування ротора, $b_{e}-$ за аксіального (ексцентричного) 
У дослідженнях використовували двигун постійного струму, тому стенд укомплектували пристроєм для випрямлення змінного струму в постійний. Для вимірювання швидкості обертання ротора використовували тахометр марки ТЧ 10-Р. Ротор обертався 3 кутовою швидкістю $\Omega_{\mathrm{i}}=80-300 \mathrm{xB}^{-1}$.

Вибір робочої рідини. Досліджували водні розчини ПАА (молекулярна маса $1,8 \cdot 10^{6}$ ) 3 масовою концентрацією 100 ppm. Концентрацію визначали за вмістом у розчині безводної речовини ПАА - $8 \%$-го технічного гелю (ТУ 6-01-1049-92, виробництва ВАТ "Оріана", м. Калуш, Івано-Франківська обл.). Під час приготування водних розчинів ПАА використовували лабораторну мішалку ММЗМ. Питому масу водного розчину ПАА визначали денсиметрами (ГОСТ 1300-57), а в'язкість віскозиметричним методом.

Розрахункові формули. Крутний момент $T$, що діє на внутрішній циліндр (ротор):

$$
T=\frac{N \cdot 30}{\pi \cdot n},
$$

де: $N$ - споживана потужність електродвигуна; $n$ - кількість обертів ротора.

Безрозмірний крутний момент на внутрішньому циліндрі у проміжку між ротором та статором (Bhambri \& Fleck, 2016):

$$
G=\frac{T}{\rho v^{2} L},
$$

де: $\rho$ - густина рідини; $v$ - кінематична в'язкість; $L$ - висота внутрішнього циліндра.

Коефіцієнт тертя у проміжку між ротором та статором (Bhambri \& Fleck, 2016):

$$
C_{f}=\frac{G}{\mathrm{Re}^{2}},
$$

де $R e$ - число Рейнольдса, яке визначали за формулою (Bhambri \& Fleck, 2016):

$$
\operatorname{Re}=\frac{\Omega_{i} r_{i}\left(r_{o}-\mathrm{r}_{i}\right)}{v},
$$

де: $\Omega_{i}$ - кутова швидкість внутрішнього циліндра, $r_{0}-$ радіус зовнішнього циліндра, $r_{i}$ - радіус внутрішнього циліндра.

Відношення радіусів циліндрів обчислили за такою формулою (Bhambri \& Fleck, 2016)

$$
\eta=\frac{r_{i}}{r_{o}} .
$$

Обговорення отриманих результатів дослідження. Спершу експерименти проводили з використанням води, як робочої рідини, в діапазоні чисел Рейнольдса від $9 \cdot 10^{4}$ до $2,8 \cdot 10^{5}$. Для масштабування крутного моменту використовували безрозмірний крутний момент $G$, який порівнювали 3 дослідженнями (Bhambri \& Fleck, 2016; Lewis \& Swinney, 1999; Wendt, 1933) (таблиця, рис. 3).

Безрозмірний крутний момент $G$, що спостерігали в наших дослідженнях для відношення радіусів циліндрів $\eta=0,8$ (див. рис. 3), добре співвідноситься з результатами (Bhambri \& Fleck, 2016; Lewis \& Swinney, 1999; Wendt, 1933). На рис. 4 представлено безрозмірний крутний момент $G$ при $R e=1 \cdot 10^{5}$ для різних значень відношення радіусів ротора і статора $\eta$. Суцільна лінія описує теоретичний безрозмірний крутний момент $G$, отриманий Вендтом (Wendt, 1933) для $R e=1 \cdot 10^{5}$ :

\begin{tabular}{|c|c|c|c|}
\hline $\begin{array}{l}\text { Відношен- } \\
\text { ня радіусів } \\
\text { ротора і } \\
\text { статора, } \eta\end{array}$ & $\begin{array}{c}\text { Діапазон дос- } \\
\text { ліджуваних } \\
\text { чисел } \\
\text { Рейнольдса, } \\
R e \\
R e\end{array}$ & $\begin{array}{c}\text { Безрозмір- } \\
\text { ний крут- } \\
\text { ний мо- } \\
\text { мент, } G\end{array}$ & Автори досліджень \\
\hline 0,724 & $2,5 \cdot 10^{3}-1 \cdot 10^{6}$ & $0,1-2000$ & $\begin{array}{c}\text { Г. Левіс, Н. Свіннеу } \\
\text { (Lewis \& Swinney, } \\
1999 \text { ) }\end{array}$ \\
\hline 0,76 & $8 \cdot 10^{4}-2,9 \cdot 10^{5}$ & $60-600$ & $\begin{array}{l}\text { П. Бхамбрі, Б. Флеск } \\
\text { (Bhambri \& Fleck, } \\
\text { 2016) }\end{array}$ \\
\hline $\begin{array}{l}0,5 ; 0,68 \\
0,85 ; 0,94\end{array}$ & $1 \cdot 10^{4}-1 \cdot 10^{5}$ & $2-70$ & $\begin{array}{c}\text { Ф. Вендт (Wendt, } \\
\text { 1933) }\end{array}$ \\
\hline 0,8 & $9 \cdot 10^{4}-2,8 \cdot 10^{5}$ & $300-500$ & власні дослідження \\
\hline
\end{tabular}

$$
G=0,23 \cdot \frac{\eta^{3 / 2}}{(1-\eta)^{7 / 4}} \cdot \mathrm{Re}^{1,7}
$$

Таблиця. Параметри досліджуваних співвідношень "ротор-статор"

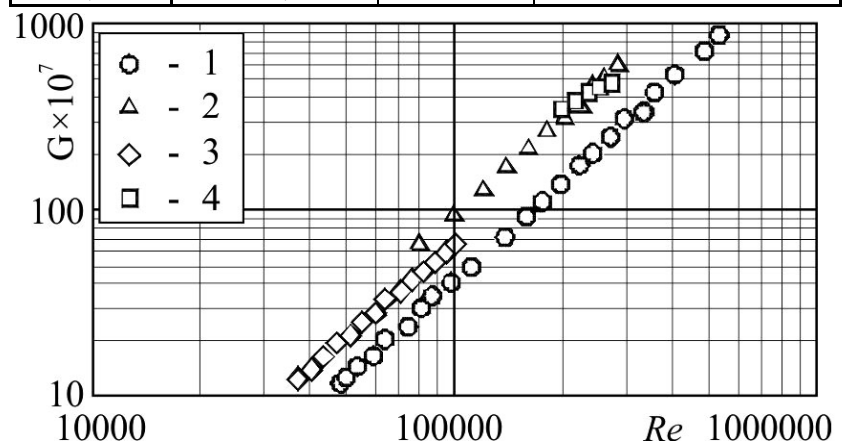

Рис. 3. Експериментальні значення безрозмірного крутного моменту G від числа Рейнольдса $R e$, отримані у цьому дослідженні (4), порівняно 3 попередніми результатами (1 - дослідження (Lewis \& Swinney, 1999), 2 - дослідження (Bhambri \& Fleck, 2016), 3 - дослідження (Wendt, 1933))

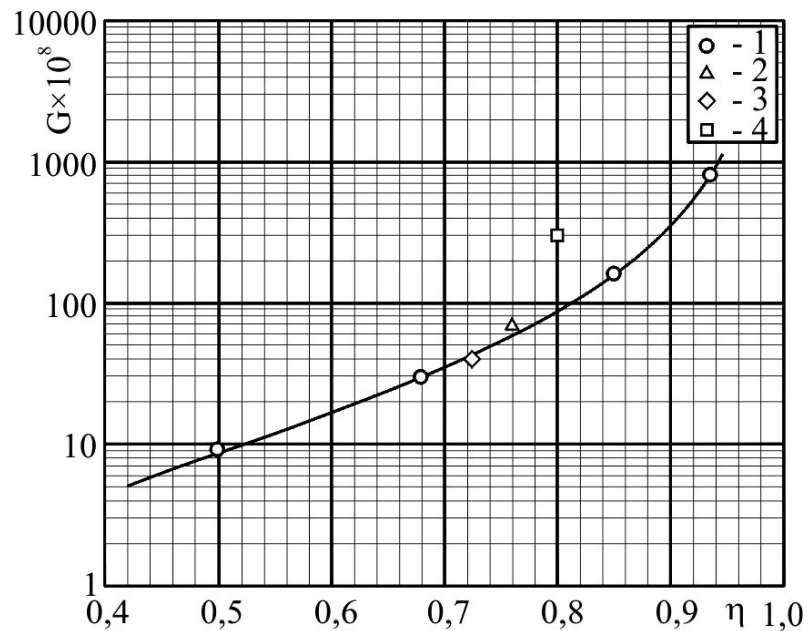

Рис. 4. Порівняння безрозмірного крутного моменту $\mathrm{G}$ для різних співвідношень радіуса $\eta$ при $R e=1 \cdot 10^{5}(1-$ дослідження (Wendt, 1933), 2 - дослідження (Bhambri \& Fleck, 2016), 3 - дослідження (Lathrop et al., 1992), 4 - власні дослідження)

Наші дослідження та дослідження (Bhambri \& Fleck, 2016; Wendt, 1933; Lathrop et al., 1992) (див. рис. 4) не збігаються, оскільки висоти досліджуваних циліндрів були різними. За неспіввісного розташування циліндрів (див. рис. 2,б) експерименти проводили при $b_{e} / b_{\kappa}=1,0$; 0,$7 ; 0,41$.

На рис. 5 показано залежність коефіцієнта тертя $C_{f}$ від числа Рейнольдса $R e$ для води і водних розчинів ПАА 3 масовою концентрацією $C=100$ ppm за відносних ширин проміжку $b_{e} / b_{\kappa}=1,0 ; 0,7 ; 0,41$. Залежність 
коефіцієнта тертя $C_{f}$ від числа Рейнольдса $R e$ за ламінарного режиму руху для значень відносної ширини проміжку $b_{e} / b_{\kappa}=1,0 ; 0,7 ; 0,41$ не змінюється до першого критичного числа Рейнольдса для ексцентричного розташування циліндрів як для води, так і для водних розчинів ПАА 3 масовою концентрацією $C=100$ ppm (див. рис. 5).

Під час досліджень водних розчинів ПАА, порівняно $з$ водою, перше критичне число Рейнольдса має менше значення. При цьому значення коефіцієнта тертя $C_{f}$, що відповідає цьому числу Рейнольдса $R e, \epsilon$ більшим. Це дає змогу приготувати водні розчини ПАА за менших кількостей обертів внутрішнього циліндра за такого ж споживання електроенергії. Тоді змішувач може бути обладнаний двигуном 3 регульованою швидкістю обертання.

3 рис. 5 видно, що за концентричного розташування циліндрів як для води, так і для водних розчинів ПАА $є$ одна твірна, яка охоплює ламінарний і турбулентний режими після першого критичного числа Рейнольдса.

Для ексцентричного розташування циліндрів розгалуження кривих залежності $C_{f}=f(R e)$ для значень $b_{e} / b_{\kappa}=0,7$ та 0,41 спостерігаємо після першого критичного числа Рейнольдса Re. При цьому значення першого критичного числа Рейнольдса є меншим, ніж за концентричного розташування циліндрів.

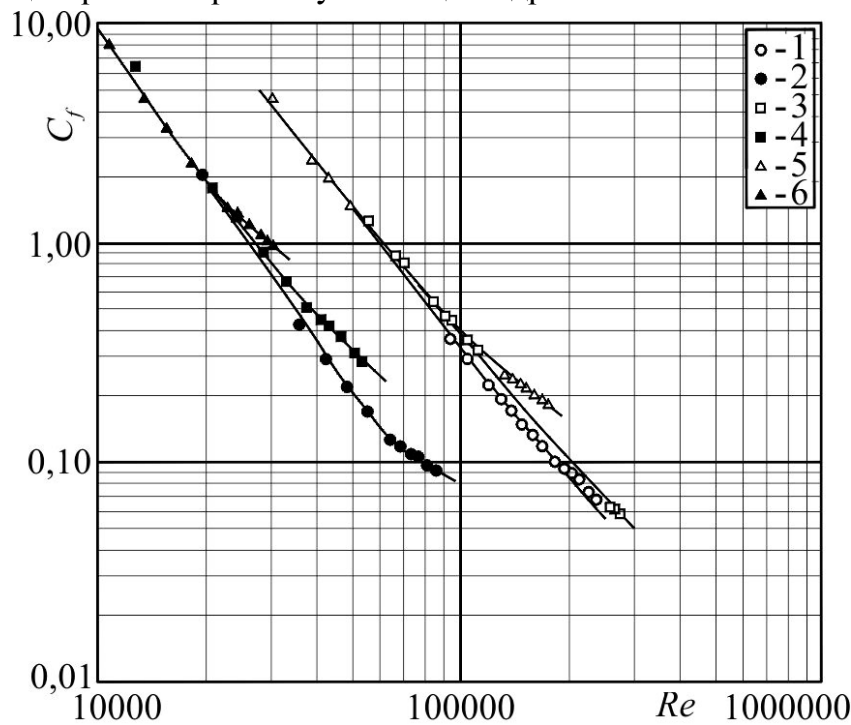

Рис. 5. Залежність коефіцієнта тертя $\mathrm{C}_{\mathrm{f}}$ у проміжку між ротором та статором від числа Рейнольдса $R e$ для води (1) за відносної ширини проміжку $b_{e} / b_{k}=1,(3)-$ при $b_{e} / b_{\kappa}=0,7,(5)$ - при $b_{e} / b_{\kappa}=0,41$ та водних розчинів ПАА (2) масовою концентрацією $\mathrm{C}=0,01 \%$ при $b_{e} / b_{\kappa}=1,(4)-$ при $b_{e} / b_{k}=0,7,(6)-$ при $b_{e} / b_{\kappa}=0,41$

Зменшення ширини проміжку призводить до збільшення коефіцієнта тертя $C_{f}$ для того самого значення числа Рейнольдса $R e$ як для води, так і для водних розчинів ПАА. Для ексцентричного розташування циліндрів перше критичне число Рейнольдса Re є однаковим як для $b_{e} / b_{\kappa}=0,7$, так і для $b_{e} / b_{\kappa}=0,41$.

Збільшення нахилу коефіцієнта тертя $C_{f}$ від числа Рейнольдса $R e$ для водних розчинів ПАА 3 концентрацією 100 ppm, порівняно з водою, узгоджується з (Каlashnikov,1998; Sreenivasan \& White, 2000; White et al., 2004). Для з'ясування збереження ефективності водного розчину ПАА $з$ концентрацією $C=100$ ррm провели експерименти за максимального значення кутової швидкості $\Omega_{\mathrm{i}}=300 \mathrm{xв}^{-1}$, що відповідало числу Рейнольдса
$\operatorname{Re}=3 \cdot 10^{4}$. Після десяти хвилин перемішування ефективність розчину не змінилась.

Висновки. Виявлено залежність коефіцієнта тертя від числа Рейнольдса, ширини проміжку між циліндрами за їх ексцентричного розташування та водних розчинів ПАА, порівняно з водою. Залежність коефіцієнта тертя від числа Рейнольдса за ламінарного режиму руху для значень відносної ширини проміжку 1,$0 ; 0,7$; 0,41 не змінюється до першого критичного числа Рейнольдса для ексцентричного розташування циліндрів. За однакових значень числа Рейнольдса для водного розчину ПАА з концентрацією 100 ррm отримано зменшення коефіцієнта тертя, порівняно з водою. Внаслідок зменшення ширини проміжку одержано збільшення коефіцієнта тертя для дослідженої концентрації водного розчину ПАА.

Отримані результати свідчать про можливість приготування водних розчинів ПАА в запропонованому змішувачі з використанням електродвигуна з регульованою швидкістю обертання.

\section{References}

Alekseev, M. Y., Ylyn, Yu. A., Yhnatchyk, V. S., \& Ylyna, S. Iu. (1991). Pokazately ekolohycheskoi bezopasnosty napornykh kollektorov system vodootvedenyia. Yzv. vuzov. Stroytelstvo y arkhytektura, 2, 73-77. [In Russian].

Zhuk, V., \& Orel, V. (1995). Problemy vykorystannia hidrodynamichno aktyvnykh dobavok dlia zbilshennia propusknoi zdatnosti kanalizatsiinykh kolektoriv. Problemy Budownictwa $i$ Inżynierii Środowiska: IV Naukowa Konferencja Rzeszowsko-Lwowska. Cz.II. Inżynieria Środowiska. Rzeszów, 15-16 wrzesień, 1995, (pp. 241-246). Rzeszów. [In Ukrainian].

Hart, J., Cotter, L., \& Vine, J. (2011). Polymer Addition to Increase Trunk Sewer Flow Capacity at the Resort Municipality of Whistler during the 2010 Winter Olympic Games, 12 r. Retrieved from: https://www.kwl.ca/sites/default/files/WEF2011_JCH_Abstract.pdf

Andrade, R. M., Pereira, A. S., \& Soares, E. J. (2015). Drag Reduction in Synthetic Seawater by Flexible and Rigid Polymer Addition Into a Rotating Cylindrical Double Gap Device. ASME J. Fluid Eng., 138(2), 1-10.

Khadom, A. A., \& Abdul-Hadi, A. A. (2014). Performance of Polyacrylamide as Drag Reduction Polymer of Crude Petroleum Flow. Ain Shams Eng. J., 5(3), 861-865.

Kozlov, L. P. (1987). Hidrodynamichnyi efekt Tomsa i yoho mozhlyvi tekhnichni zastosuvannia. Visnyk AN URSR, 1, 23-33. [In Ukrainian].

Povkh, I. L. (1982). Zmenshennia turbulentnoho tertia - osnovne dzherelo ekonomii enerhii. Visn. AN URSR, 11, 66-74. [In Ukrainian].

Kaboorani, A., \& Riedl, B. (2015). Surface modification of cellulose nanocrystals (CNC) by a cationic surfactant. Industrial Crops and Products, 65, 45-55. https://doi.org/10.1016/j.indcrop.2014.11.027

Wagih Abu Rowin, R. Sean Sanders, \& Sina Ghaemi (2018). A Recipe for Optimum Mixing of Polymer Drag Reducers. Journal of Fluids Engineering, 140, 111-402.

Cherniuk, V. V., \& Pitsyshyn, B. S. (). Zaiavka na vydachu patenta: Ukraina, Zmishuvach. a201612982; zaiavn. 19.01.2017. [In Ukrainian].

Taylor, G. I. (1923). Stability of a Viscous Liquid Contained between Two Rotating Cylinders. Philosophical Transactions of the Royal Society A: Mathematical, Physical and Engineering Sciences. https://doi.org/10.1098/rsta.1923.0008

Davey, A. (1962). The growth of Taylor vortices in flow between rotating cylinders. Journal of Fluid Mechanics, 14(3), 336. https://doi.org/10.1017/S0022112062001287

Cole, J. A. (1976). Taylor-vortex instability and annulus-length effects. Journal of Fluid Mechanics, 75(1), 1. https://doi.org/10.1017/S0022112076000098 
Huisman, S. G., Scharnowski, S., Cierpka, C., Kähler, C. J., Lohse, D., \& Sun, C. (2013). Logarithmic Boundary Layers in Strong Taylor-Couette Turbulence. Physical Review Letters, 110(26), 264 501. https://doi.org/10.1103/PhysRevLett. 110.264501

Adebayo, D., Al-Ameri, J., Tyukin, I., \& Rona, A. (2018). Linear stability analysis of the flow between rotating cylinders of wide gap. European Journal of Mechanics / B Fluids, 72, 567-575. https://doi.org/10.1016/j.euromechflu.2018.07.002

Adebayo, D., \& Rona, A. (2015). The persistence of vortex structures between rotating cylinders in the $10^{6}$ Taylor number range. Int. Rev. Aerosp. Eng. (I.RE.AS.E), 8(1), 16-25.

Campolo, M., Simeoni, M., Lapasin, R., \& Soldati, A. (2015). Turbulent Drag Reduction by Biopolymers in Large Scale Pipes. Journal of Fluids Engineering, 137(4), 041102. https://doi.org/10.1115/1.4028799

Jones, W. M., \& Marshall, D. E. (1969). Relaxation effects in Couette flow between rotating cylinders. British Journal of Applied Physics, 2(2), 809-814.

Groisman, A., \& Steinberg, V. (1996). Couette-Taylor Flow in a Dilute Polymer Solution. Physical Review Letters, 77(8), 1480-1483. https://doi.org/10.1103/PhysRevLett.77.1480

Yi, M.-K., \& Kim, C. (1997). Experimental studies on the Taylor instability of dilute polymer solutions. Journal of Non-Newtonian Fluid Mechanics, 72(2-3), 113-139.

Sugiyama, K., Calzavarini, E., \& Lohse, D. (2008). Microbubbly drag reduction in Taylor-Couette flow in the wavy vortex regime. Journal of Fluid Mechanics, 608 https://doi.org/10.1017/S0022112008001183

Koeltzsch, K., Qi, Y., Brodkey, R. S., \& Zakin, J. L. (2003). Drag reduction using surfactants in a rotating cylinder geometry. Experiments in Fluids, 34(4), 515-530. https://doi.org/10.1007/s00348003-0590-4

Ashrafi, N. (2011). Stability analysis of shear-thinning flow between rotating cylinders. Applied Mathematical Modelling, 35(9), 44074423. https://doi.org/10.1016/i.apm.2011.03.010

Labkovich, O. N. (2017). Reduction of Friction Losses due to the Vortex Flow of the Magnetic Fluid Caused by the Additives of Carbon Nanotubes Energetika. Pros. SIS Higher Educ. Inst. and Power Eng. Assoc., 60(3), 265-275.

Dutcher, C. S., \& Muller, S. J. (2009). The effects of drag reducing polymers on flow stability: Insights from the Taylor-Couette problem. Korea-Australia Rheology Journal, 21(4), 223-233.

Greidanus, J., Delfos, R., \& Westerweel, J. (2011). Drag reduction by surface treatment in turbulent Taylor-Couette flow. Journal of
Physics: $\quad$ Conference Series, 318(8),

082016 https://doi.org/10.1088/1742-6596/318/8/082016

Srinivasan, S., Kleingartner, J. A., Gilbert, J. B., Cohen, R. E., Milne, A. J. B., \& McKinley, G. H. (2015). Sustainable rag Reduction in Turbulent Taylor-Couette Flows by Depositing Sprayable Superhydrophobic Surfaces. Physical Review Letters, 114(1), 014501. https://doi.org/10.1103/PhysRevLett.114.014501

Eskin, D. (2014). Applicability of a Taylor-Couette device to characterization of turbulent drag reduction in a pipeline. Chemical Engineering Science, 116, 275-283. https://doi.org/10.1016/j.ces.2014.05.016

Greidanus, A. J., Delfos, R., Tokgoz, S., \& Westerweel, J. (2015). Turbulent Taylor-Couette flow over riblets: drag reduction and the effect of bulk fluid rotation. Experiments in Fluids, 56, 107.

Popadiuk, I. Yu., Pitsyshyn, B. S., \& Orel, V. I. (2018). Increase in friction in the Taylor-Coette flow using sodium carboxymethyl cellulose. Scientific Bulletin of UNFU, 28(10), 96-100. https://doi.org/10.15421/40281020

Pallavi Bhambri, \& Brian Fleck. (2016). Drag reduction using high molecular weight polymersin Taylor-Couette flov. International Journal of Mechanical and Production Engineering Research and Development, 6(1), 59-72.

Lewis, G. S., \& Swinney, H. L. (1999). Velocity structure functions, scaling, and transitions in high-Reynolds-number Couette-Taylor flow. Physical Review. E, Statistical Physics, Plasmas, Fluids, and Related Interdisciplinary Topics, $59(5$ Pt B), 5457-5467. https://doi.org/10.1103/PhysRevE.59.5457

Wendt, F. (1933). Turbulente Strömungen zwischen zwei rotierenden konaxialen Zylindern. Ingenieur-Archiv, 4(6), 577-595. https://doi.org/10.1007/BF02084936

Lathrop, D. P., Fineberg, J., \& Swinney, H. L. (1992). Transition to shear-driven turbulence in Couette-Taylor flow. Physical Review A, 46(10), 6390-6405. https://doi.org/10.1103/PhysRevA.46.6390

Kalashnikov, V. N. (1998). Dynamical similarity and dimensionless relations for turbulent drag reduction by polymer additives. Journal of Non-Newtonian Fluid Mechanics, 75(2-3), 209-230. https://doi.org/10.1016/S0377-0257(97)00093-1

Sreenivasan, K. R., \& White, C. M. (2000), The onset of drag reduction by dilute polymer additives, and the maximum drag reduction asymptote. J. Fluid Mech., 409, 149-164.

White, C. M., Somandepalli, V. S. R., \& Mungal, M. G. (2004). The turbulence structure of drag-reduced boundary layer flow. Experiments in Fluids, 36(1), 62-69. https://doi.org/10.1007/s00348-003$\underline{0630-0}$

\section{USE OF THE MIXER OF MODERN CONSTRUCTION FOR PREPARATION OF THE POLYACRYLAMIDE WATER SOLUTIONS IN THE TAYLOR-COUETTE FLOW}

Paddle mixers with a low rotation speed are usually used for the preparation of aqueous solutions of hydrodynamically active polymers. The problem is in potential destruction of polymers, which cause decreasing or complete breakup of the influence of hydrodynamically active polymers on hydraulic resistance. In order to prevent the destruction of the molecules of hydrodynamically active polymers, a new mixer was proposed, consisting of a rotor located in a cylindrical stator, with the possibility of its horizontal movement, which causes a change in the eccentricity between the rotor and the stator. The aim of the paper is to study the preparation of aqueous solutions of hydrodynamically active polymers in the proposed mixer with the Taylor-Couette flow. The results of experimental studies of the effect of the eccentricity of the rotor and stator so as the concentration of polyacrylamide solutions on the friction coefficient in the Taylor-Couette flow are presented. The annular gap between the rotor with a diameter of $113 \mathrm{~mm}$ and the stator with a diameter of $142 \mathrm{~mm}$ was filled with aqueous solutions of polyacrylamide with a mass concentration of $100 \mathrm{ppm}$. The annular gap between the surfaces of the cylinders, which corresponds to their coaxial arrangement, was transformed into a confusor-diffusor gap when the position of the outer cylinder changed relatively to the inner one. The dependence of the friction coefficient on the Reynolds number at various eccentricity values are obtained for the aqueous solutions of polyacrylamide with $\mathrm{C}=100 \mathrm{ppm}$. Increasing of the Reynolds number causes a decreasing of the friction coefficient as for the polyacrylamide solution, so for water. For the same Reynolds numbers friction coefficient for the polyacrylamide solution is less comparing the water. Decreasing of the gap width causes increasing of the friction coefficient for the studied polyacrylamide solution. The first critical Reynolds number for the polyacrylamide solution is less comparing with the water. At the same time the friction coefficient at corresponding Reynolds number for the polyacrylamide solution is higher. The results indicate the possibility of preparing the polyacrylamide aqueous solutions in the proposed mixer using a motor with adjustable rotational speed.

Keywords: eccentric cylinders; rotor; friction coefficient; torque; Taylor-Couette flow; Reynolds number. 